This item was submitted to Loughborough's Research Repository by the author.

Items in Figshare are protected by copyright, with all rights reserved, unless otherwise indicated.

\title{
Laser polishing of selective laser melted components
}

PLEASE CITE THE PUBLISHED VERSION

http://dx.doi.org/10.1016/j.jjmachtools.2015.05.002

\section{PUBLISHER}

(c) Elsevier

\section{VERSION}

AM (Accepted Manuscript)

\section{PUBLISHER STATEMENT}

This work is made available according to the conditions of the Creative Commons Attribution-NonCommercialNoDerivatives 4.0 International (CC BY-NC-ND 4.0) licence. Full details of this licence are available at: https://creativecommons.org/licenses/by-nc-nd/4.0/

\section{LICENCE}

CC BY-NC-ND 4.0

\section{REPOSITORY RECORD}

Marimuthu, Sundar, A. Triantaphyllou, M. Antar, D.I. Wimpenny, H. Morton, and M. Beard. 2019. "Laser Polishing of Selective Laser Melted Components”. figshare. https://hdl.handle.net/2134/18224. 


\title{
Laser Polishing of Selective Laser Melted Components
}

S. Marimuthu ${ }^{\mathrm{a}^{*}, \mathrm{c}}$, A. Triantaphyllou ${ }^{\mathrm{a}}$, M. Antar ${ }^{\mathrm{a}}$, D. Wimpenny ${ }^{\mathrm{a}}$, H. Morton $^{\mathrm{b}}$, M. Beard $^{\mathrm{b}}$

${ }^{\mathrm{a}}$ The Manufacturing Technology Centre, Coventry, UK

${ }^{\mathrm{b}} 3 \mathrm{~T}$ RPD LTD, Berkshire, UK

${ }^{\mathrm{c}}$ Loughborough University, Loughborough, UK

\begin{abstract}
The shape complexities of aerospace components are continuously increasing, which encourages industries to refine their manufacturing processes. Among such processes, the selective laser melting (SLM) process is becoming an economical and energy efficient alternative to conventional manufacturing processes. However, dependent on the component shape, the high surface roughness observed with SLM parts can affect the surface integrity and geometric tolerances of the manufactured components. To account for this, laser polishing of SLM components is emerging as a viable process to achieve high-quality surfaces. This report details an investigation carried out to understand the basic fundamentals of continuous wave laser polishing of SLM samples. A numerical model, based on a computational fluid dynamic formulation, was used to assist the understanding of melt pool dynamics, which significantly controls the final surface roughness. The investigation identified the input thermal energy as the key parameter that significantly affect the melt pool convection, and essentially controls the surface quality. Minimum meltpool velocity is essential to achieve wider laser polished track width with good surface finish. Experimental results showed a reduction of surface roughness from $10.2 \mu \mathrm{m}$ to $2.4 \mu \mathrm{m}$ after laser polishing with optimised parameters. Strategies to control the surface topology during laser polishing of SLM components are discussed.
\end{abstract}

Keywords: Melting, SLM, Laser, Polishing, CFD, Modelling, Simulation.

\footnotetext{
* Corresponding author

E-mailaddress: Sundar.Marimuthu@the-mtc.org (S. Marimuthu)
} 


\section{Introduction}

Currently, aero-engine components are produced by combined manufacturing processes that include forging, rolling and subtractive CNC mechanical machining [1]. Use of these processes to machine certain components from solid blocks can lead to massive material wastage [2] and high production times. The SLM process has, on the other hand, demonstrated its capability in the production of parts with complex 3D geometries [3]. Over the last few years this process has gained increasing attention due to the rapid development in the capabilities of additive manufacturing $[4,5]$. Despite the widely recognised merits of SLM in the manufacture of components in general, a negative aspect of the process is related to the unacceptable surface finish which could significantly limit the industrial uptake. High surface roughness can lead to unacceptable tolerances, increased friction and potentially becoming a source of fatigue crack initiation [6].

Conventional abrasive blasting and mechanical polishing do not offer an acceptable solution for precision components, which require selective processing [7, 8]. Electro chemical polishing and electropolishing have been reviewed by some researchers to improve the surface finish of SLM parts, but were found to have environmental issues [9]. Recently, laser polishing $[6,10]$ has gained interest as it has shown potential for selective polishing of metals and alloys. Laser polishing involves melting a thin layer of the substrate, with surface tension causing the material to flow from peaks to valleys. In laser polishing the material is not removed, but is relocated as a molten pool.

Laser polishing as a technique to reduce surface roughness has been investigated by various researches $[11,12]$ who have shown promising results. Laser polishing of SLM sintered titanium and nickel-based alloys were studied by Kumstel [11], who concluded that the polished surface mainly depended on the surface material, initial topography and laser beam density. Laser polishing of Inconel-718 parts built by laser metal deposition (LMD) has been 
investigated by Dadbakhsh [13], who focused on identifying the optimum process parameters to achieve an $80 \%$ reduction in surface roughness. Laser polishing has been proven to enhance the surface roughness of metals, alloys and ceramics, with no significant distortion to the parts. However, majority of the available research concentrated on parametric studies of laser polishing without any analysis on the underlying significance of melt pool dynamics.

In the present study, an experimental investigation into the continuous wave fibre laser polishing of SLM parts was undertaken to achieve a smooth surface profile, through the control of laser process parameters and analysis of melt pool dynamics. Melt pool dynamics significantly influence the surface profile, hence this investigation focuses on understanding the effects of melt pool dynamics on surface topology and roughness. Along with experimental results, a three-dimensional computational fluid dynamic (CFD) model was developed to study the effect of laser polishing parameters on melt pool dynamics and surface topology. Temperature field, velocity field and melt pool geometry were modelled for various scanning parameters. The calculated melt pool geometry and surface conditions were compared with experimental results obtained under similar parameters, in order to explain the findings.

\section{Material and Methods}

The base materials used in this study were SLM manufactured Ti-6Al-4V components of size $40 \times 10 \times 5 \mathrm{~mm}$ produced at $45^{\circ}$ build angle, and supplied by 3T RPD Ltd. Ti-6Al-4V samples were used as the test material due its challenges with laser processes, including its susceptibility to rapid oxidisation [14, 15] and stress cracking [16]. However the fundamental results discussed in this paper is applicable to most metals and alloys. The chemical composition of the base material used in the study is given in Table 1. The average surface roughness of the base material is around $10.2 \mu \mathrm{m}$. 
Table 1 Chemical compositions for Ti-6Al-4V used in the study (Wt.\%)

\begin{tabular}{|c|c|c|c|c|c|c|c|}
\hline $\mathrm{Al}$ & $\mathrm{V}$ & $\mathrm{O}$ & $\mathrm{N}$ & $\mathrm{C}$ & $\mathrm{H}$ & $\mathrm{Fe}$ & $\mathrm{Ti}$ \\
\hline $5.5-6.75$ & $3.5-4.5$ & 0.2 & 0.05 & 0.08 & 0.015 & 0.30 & Bal. \\
\hline
\end{tabular}

The experimental setup, shown schematically in Fig. 1, was used to perform the laser polishing experiment, and to determine the process window that will give the best surface morphology. Laser polishing was performed using a continuous wave fibre laser at 10701090nm wavelength, with a maximum power output of 200W. A co-axial nozzle assembly with an exit diameter of $2.5 \mathrm{~mm}$ and a $120 \mathrm{~mm}$ focal length lens was used to focus the beam to the work piece surface. The distance between the nozzle and workpiece was maintained at $5 \mathrm{~mm}$ so as to achieve the required beam size of $0.5 \mathrm{~mm}$. Argon gas (99\%) was used to protect the melt pool from oxidization. Initial trial shows optimal shielding of the melt pool at a gas pressure of $1.0 \mathrm{bar}$ and mass flow rate of $81 / \mathrm{min}$. Samples were irradiated in a horizontal position with the vertical beam interaction at room temperature. The workpiece was held on a numerically controlled $\mathrm{X}-\mathrm{Y}-\mathrm{Z}$ stage set. For each parameter set, three sets of samples were produced to eliminate the effect of systematic errors.

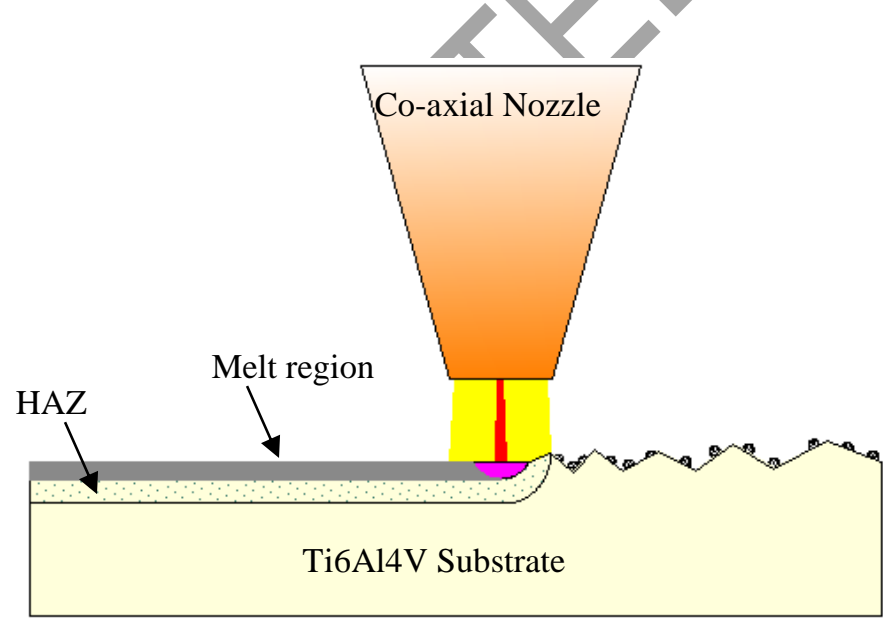

(a)

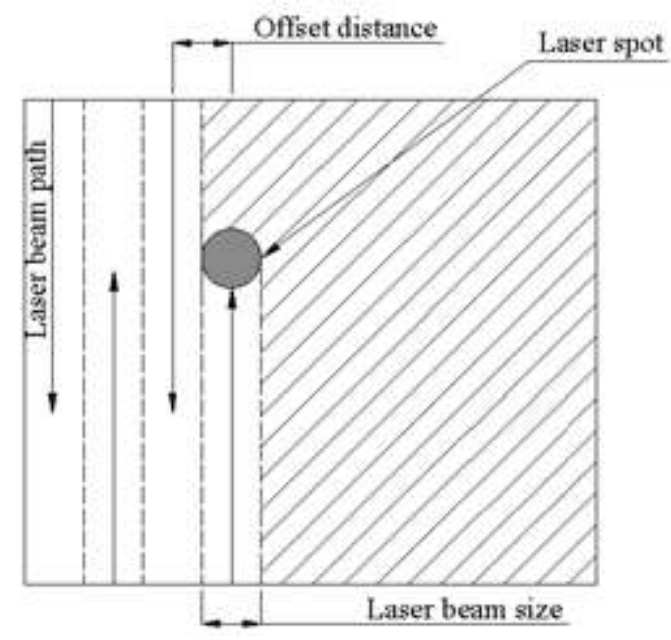

(b)

Figure 1 Schematic of (a) the laser polishing experimental setup (b) the beam offset strategy

The energy density delivered to the work piece plays a major role [17] in the thermal cycle, fluid dynamics, microstructure and consequent surface profile, and is controlled by changing 
the input power and scanning speed [18]. Pre-experimental trials were used to assess the range of feasible polishing parameters, with the objective of obtaining uniform laser polishing track.

The metallographic samples were prepared according to ASTM E3-11 standard and then etched with Kalling's reagent to reveal the microstructure. Surface morphology and crosssectional microscopic characteristics of the laser polished samples were examined by Keyence digital microscope. More detailed examination of the surface morphology was undertaken by scanning electron microscopy (SEM), where, a Hitachi S-3400N operating in secondary electron mode, equipped with an energy dispersive X-ray spectroscopy (EDX) detector, was employed. A MahrSurf surface profiler was used to measure the surface roughness and a Buehler micro-hardness tester was used to measure the hardness.

\section{Numerical Modeling Methodology}

The CFD analysis was performed to model the physical phenomena in the laser polishing, heat transfer and fluid flow and was performed using finite volume based code, FLUENT. The mathematical model used in this work was based on the Navier-Stokes equations with the Reynolds method of averaging the time-dependent equations (RANS). The governing equations [19] were composed of the conservation of mass, conservation of momentum, and conservation of energy, which are given by equations (1)-(3):

$$
\begin{aligned}
& \frac{\partial \rho}{\partial t}+\nabla(\rho \vec{v})=0 \\
& \frac{\partial}{\partial t}(\rho v)+\nabla(\rho \vec{v} \vec{v})=-\nabla p+\mu \nabla^{2} v+S_{w}
\end{aligned}
$$

where $\rho$ is the density, $t$ is the time, $\vec{v}$ is the melt pool velocity in respective directions, $p$ is the pressure force, $\mu$ is the viscosity and $S_{w}$ is the momentum sink. 
The energy equation is written in terms of the sensible enthalpy. An appropriate formulation of the latent heat function plays a pivotal role in ensuring that the results from the energy equation are consistent with phase-change considerations.

$\frac{\partial}{\partial t}(\rho H)+\nabla(\rho \vec{v} H)=\nabla(k \nabla T)+S$

where $H$ is enthalpy, $k$ is the thermal conductivity, $T$ is the temperature and $S$ is the volumetric heat source. Enthalpy of the material is computed as the sum of sensible enthalpy (h) and latent heat $(\Delta H)$.

$H=h+\Delta H$

$h=h_{r e f}+\int_{T_{r e f}}^{T} C_{p} d T$

where $h_{r e f}$ is the reference enthalpy, $T_{r e f}$ is the reference temperature and $C_{p}$ is the specific heat at constant pressure. Latent heat content $(H)$ can be written in terms of latent heat of the material $(L)$.

$\Delta H=\beta L$

where $\beta$ is the liquid fraction, which is defined as

$\beta=\left\{\begin{array}{ll}1 & T>T_{1} \\ \left(T-T_{s}\right) /\left(T_{1}-T_{s}\right) & T_{s} \leq T \leq T_{1} \\ 0 & T<T_{s}\end{array}\right\}$

where $T_{l}$ is the liquids temperature and $T_{s}$ is the solidus temperature. The values of $\beta$, ranges between 0 and 1, defining the extent of melting. The mushy zone is treated as a porous medium in momentum equations. A momentum sink is added to the momentum equation (Eq. 2) to extinguish velocities in the solid region. The momentum sink $\left(S_{w}\right)$ due to reduced porosity in the mushy zone can be written as: 
$\mathrm{S}_{w}=\frac{(1-\beta)^{2}}{\left(\beta^{3}+\xi\right)} A_{m}(w)$

where $\xi$ is a small number (0.001) to avoid division by zero and $A_{m}$ is the mushy zone constant.

Heat loss due to convection and radiation was considered over all the surfaces and a Gaussian heat flux (Eq. 9) was used as the input laser heat source. Heat flux input with heat loss due to convection and radiation [20] is expressed as:

$k \nabla T=q(x, y)-h_{c}\left(T-T_{\infty}\right)$

where $h_{c}$ is the heat transfer coefficient, $T_{\infty}$ is the ambient temperature and $q(x, y)$ is the laser heating source given by:

$q(x, y)=P_{x, y}\left(1-r_{f}\right)$

where $r_{f}$ is the reflectivity of the material and $\mathrm{P}_{x, y}$ is the Gaussian heat flux, which is given by:

$P_{x, y}=\frac{P}{r_{b}^{2} \pi} \exp \left(-\frac{2 r}{r_{b}^{2}}\right)$

where $P$ is the total laser power, $r$ is radial position within the beam and $r_{b}$ is the beam diameter.

The fluid flow in the melt pool is driven by the combination of surface tension, viscous force and buoyancy force [21]. On the top and bottom surfaces, the shear stress $(\tau)$ caused by the variation of surface tension due to temperature difference is given by:

$\tau=\frac{\partial \sigma}{\partial T} \nabla_{s} T$

where, $\frac{\partial \sigma}{\partial T}$ is surface tension gradient and $\nabla_{s} T$ is surface temperature gradient. During the computation, the surface tension gradient is expressed as a function of the surface 
temperature. The shear stress given by equation (10) is applied to the momentum equations (Eq. 3).

The melt pool surface displacements in this model were incorporated due to the effect of two phenomena. The first one is the surface deformation produced by vaporisation induced recoil force, which is extremely minimal for laser polishing. The second and predominant one is due to the surface tension gradient, which influences the direction of melt pool movement, which eventually influences the laser polished surface profile. The surface nodes on the melt pool were moved according to the melt pool velocity [22]. The adaptive mesh refinement was used in the CFD analysis so as to predict the new surface topology at a realistic accuracy at every time step. Also, the model is based on the assumptions that the laser gas dynamic parameters like, shielding gas jet, nozzle stand-off and nozzle exit diameter have insignificant effects on melt pool geometry, thermal characteristic and laser polished shape characteristic.

In order to regulate the laser heat source and to track the polished surface profile, a compiled user defined function (UDF) file was introduced to the prepared FLUENT CASE file. The UDF was written in the $C$ programming language and linked to the FLUENT solver. Temperature dependent material properties $[23,24]$ were used for numerical modelling.

\section{Results}

The experiment was carried under two different conditions in order to determine the best polishing parameters. Initially, the experiments were carried out using a single linear laser beam track to determine the viability of the process, and to find the key process variables. This knowledge was then applied to polishing relatively larger areas through a series of linear scans (as shown in Fig. 1(b)) with different values of laser beam offset between scan tracks. 
Table-2 Experimental design used for linear track experiments

\begin{tabular}{|c|c|}
\hline Power $(\mathrm{W})$ & $200 ; 180 ; 160 ; 140 ; 120 ; 100 ; 80 ; 60 ; 50$ \\
\hline $\begin{array}{c}\text { Speed } \\
(\mathrm{mm} / \mathrm{min})\end{array}$ & $200 ; 400 ; 600 ; 800 ; 1000 ; 1200 ; 1400 ; 1600 ; 1800 ; 2000 ; 2200 ; 2400$ \\
\hline \multicolumn{2}{|c|}{ beam size $=0.5 \mathrm{~mm}$, gas type $=$ argon, mass flow $=81 / \mathrm{min}$} \\
\hline
\end{tabular}

An initial experiment was carried out based on change of one-factor-at-a-time to determine the best melting characteristics that will give good surface finish and large melt track width. Table 2 shows the factorial experimental design implemented for single track scans to determine the range of optimal speed and power. Typical optical micrographs of laser polished linear tracks are show in Fig. 2. As can be seen from the figures, three distinct features (low melting-100-140W; good polished region-160-180W; surface patterns-200W) were observed within the process range (changing laser power). Low input energy $(<120 \mathrm{~W})$ resulted in a negligible melt pool width. This is due to the nonlinear melt pool dynamics observed in CW laser polishing of metals and alloys. More explanation is given in numerical simulation part.

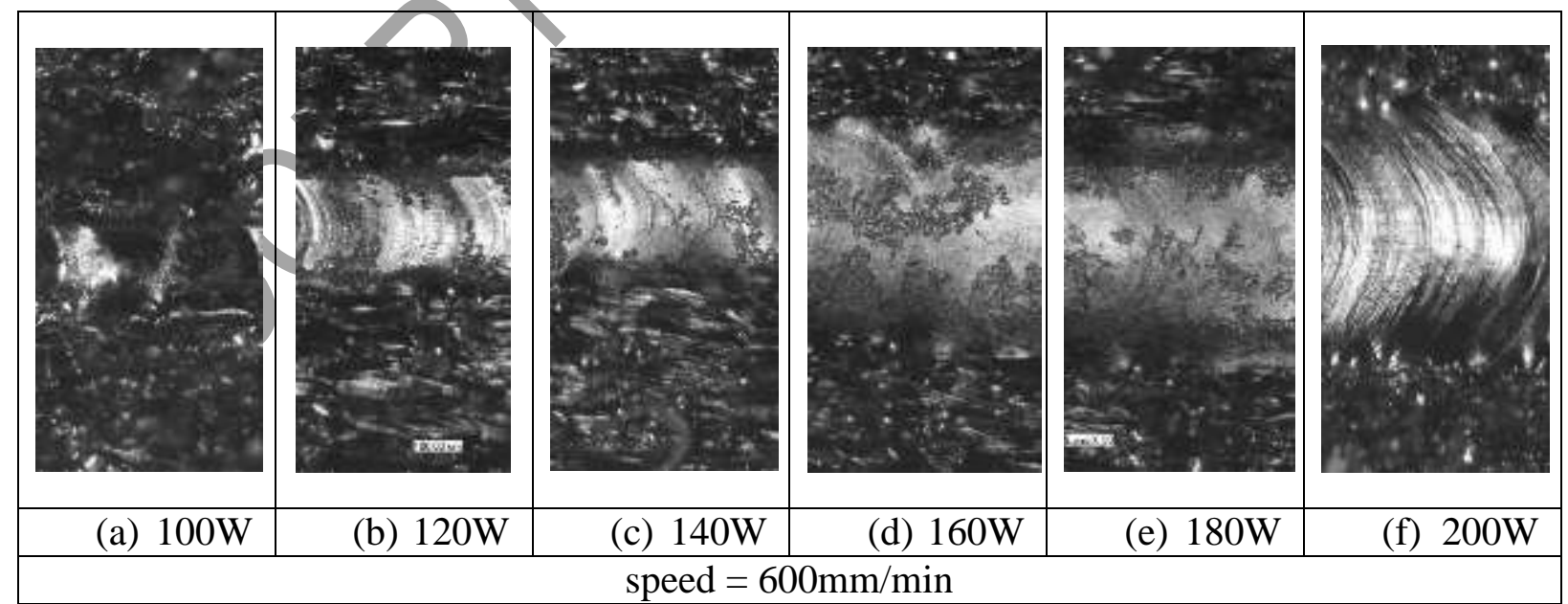

Figure 2 Optical microscopic images of laser polished linear track for various laser power 


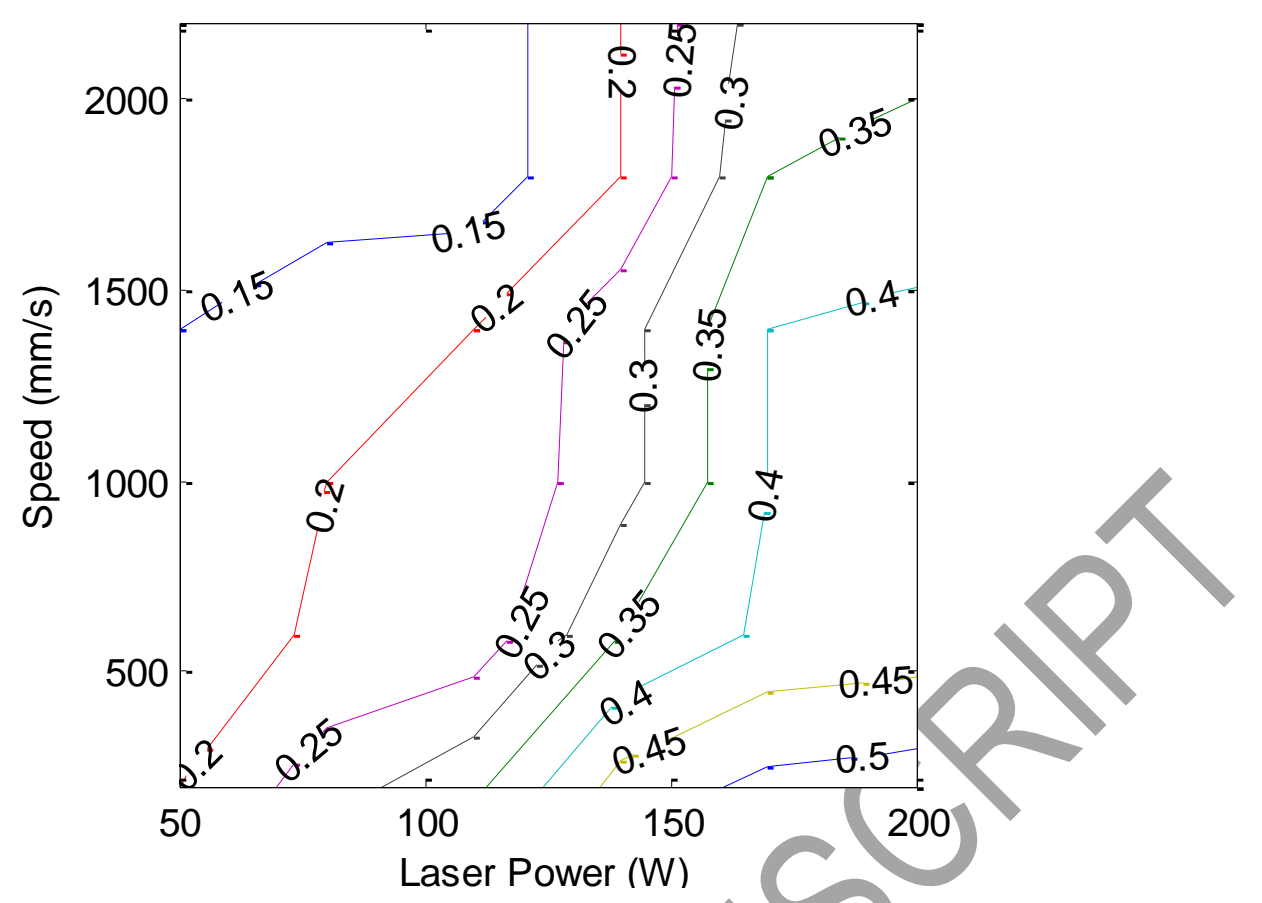

Figure 3 Effect of power and speed on laser melted track width (number on line contour indicates melt width in $\mathrm{mm}$ )

Fig. 3 shows the variation in laser track width as a function of laser power and speed. Higher track width is preferred for a cost-effective laser polishing. As can be seen from the figure, a non-linear variation of track width was found with increasing laser power or speed. A reasonable track width of $0.41 \mathrm{~mm}$ and smooth surface morphology was achieved with a laser power range of $150-180 \mathrm{~W}$ and a speed range of $500-1000 \mathrm{~mm} / \mathrm{min}$. Laser powers below $150 \mathrm{~W}$, or scanning speeds greater than $1000 \mathrm{~mm} / \mathrm{min}$, failed to produce a reasonable melt pool width. Powers higher than $180 \mathrm{~W}$ or scanning speeds less than $500 \mathrm{~mm} / \mathrm{min}$ produced significant surface ripples, which can increase the surface roughness. The formation of surface ripples should be attributed to the meltpool convention at the laser irradiated zone.

The work analysing polishing of single tracks was extended to analyse polishing of larger areas through a series of overlapping laser beam tracks in alternating directions. The strategy for scanning large areas is shown in Figure 1(b). Table 3 shows the experimental design values, which were based on the observations from single track scans. 
Table 3 Experimental plan used for laser polishing over large area

\begin{tabular}{|c|c|}
\hline Beam offset $(\mathrm{mm})$ & $0.3 ; 0.35 ; 0.4 ; 0.45 ; 0.5 ; 0.55$ \\
\hline Speed $(\mathrm{mm} / \mathrm{s})$ & $500 ; 625 ; 750 ; 875 ; 1000$ \\
\hline Power $(\mathrm{W})$ & $150 ; 157.5 ; 165 ; 172.5 ; 180$ \\
\hline \multicolumn{2}{|c|}{ beam size $=0.5 \mathrm{~mm}$, gas type $=$ argon $;$ mass flow $=81 / \mathrm{min}$} \\
\hline
\end{tabular}

Figure 4 illustrates the interaction effects between laser power, scanning speed and beam offset on the surface roughness value (Ra). As noted from the figure, increase in beam offset deteriorates the surface finish, irrespective of laser power and speed. The improvement in surface finish is attributed to repeated melting, which effectively removes surface imperfections. However, excessive thermal input can cause metallurgical damages, hence it should be controlled. A minimum surface roughness of $2.4 \mu \mathrm{m}$ Ra was achieved with a laser power of $160 \mathrm{~W}$, scanning speed of $750 \mathrm{~mm} / \mathrm{min}$ and a beam offset of $0.35 \mathrm{~mm}$.

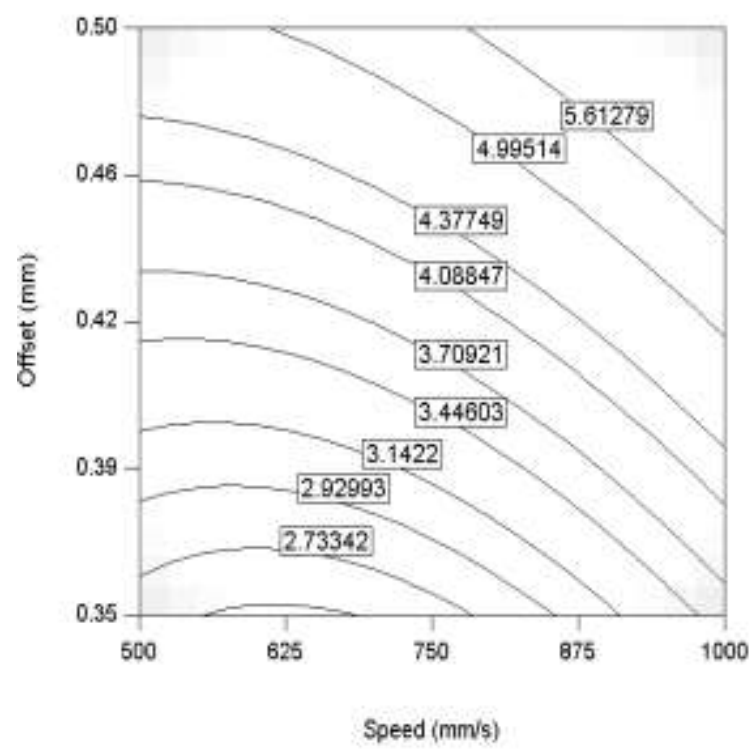

(a)

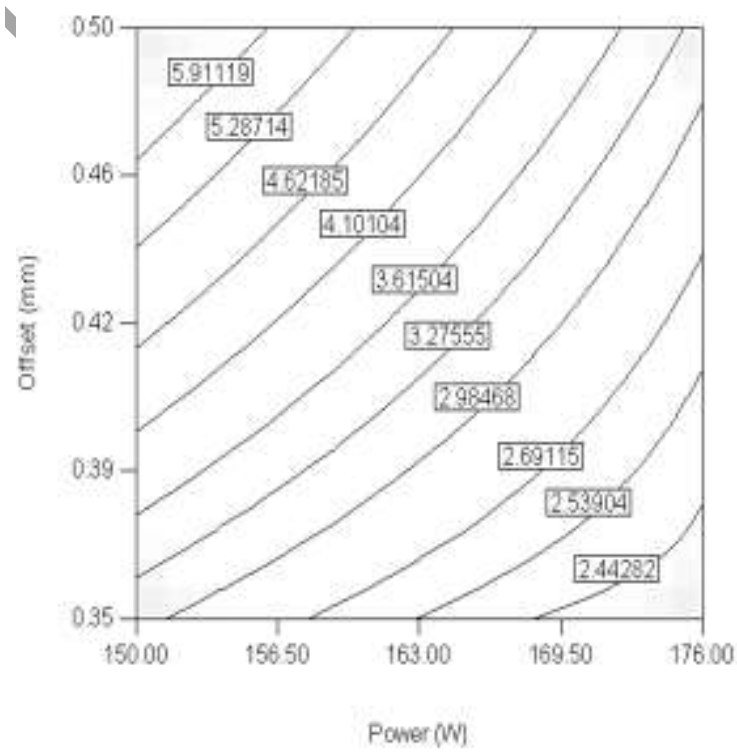

(b)

Figure 4 Interaction effect of power, speed and beam offset on surface roughness (numbers on the contour lines represent the surface roughness $R_{a}$ in $\mu \mathrm{m}$ ) 


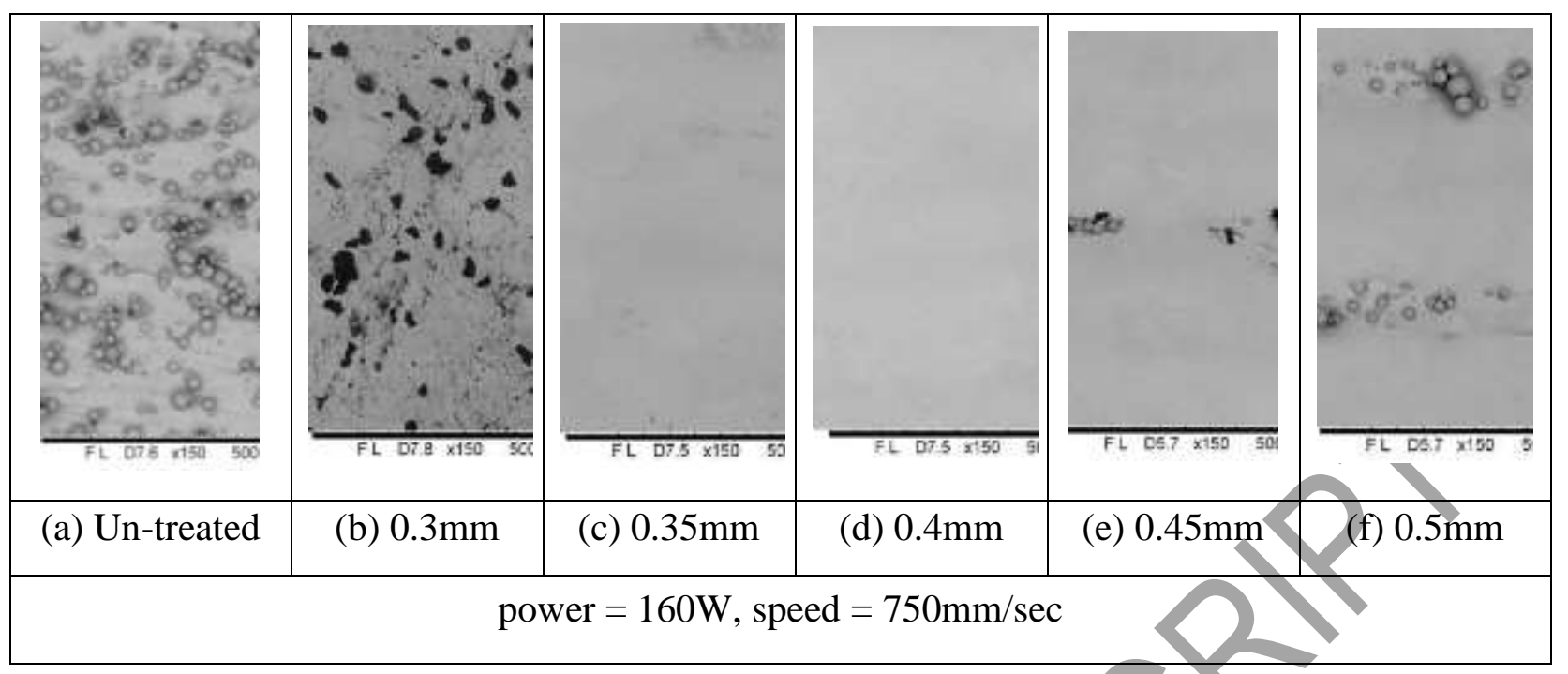

Figure 5 Effect of laser beam offset in mm on laser polished surface morphology

SEM images of laser polished surfaces are shown in Figure 5. As can be seen from the figure, a large beam offset $(>0.4 \mathrm{~mm})$ resulted in insufficient melting of the interface (between two tracks), whilst a smaller beam offset resulted in significant damage of surface morphology due to excessive melting. A smaller beam offset resulted in high residual heating and consequently, some of the powder yaporised/decomposed appearing as a black residue in the image (Figure 5b). To achieve a better surface characteristic, the surface must be free from un-melted particles and thermal damage. Figure 6 shows the surface composition of the laser polished area for various beam offset, measured using an energy dispersive X-ray spectroscopy. A slight increase (1-2\%) in the concentration of oxygen and carbon were noticed for samples with offset less than $0.35 \mathrm{~mm}$ and parameters in this range should be avoided. 


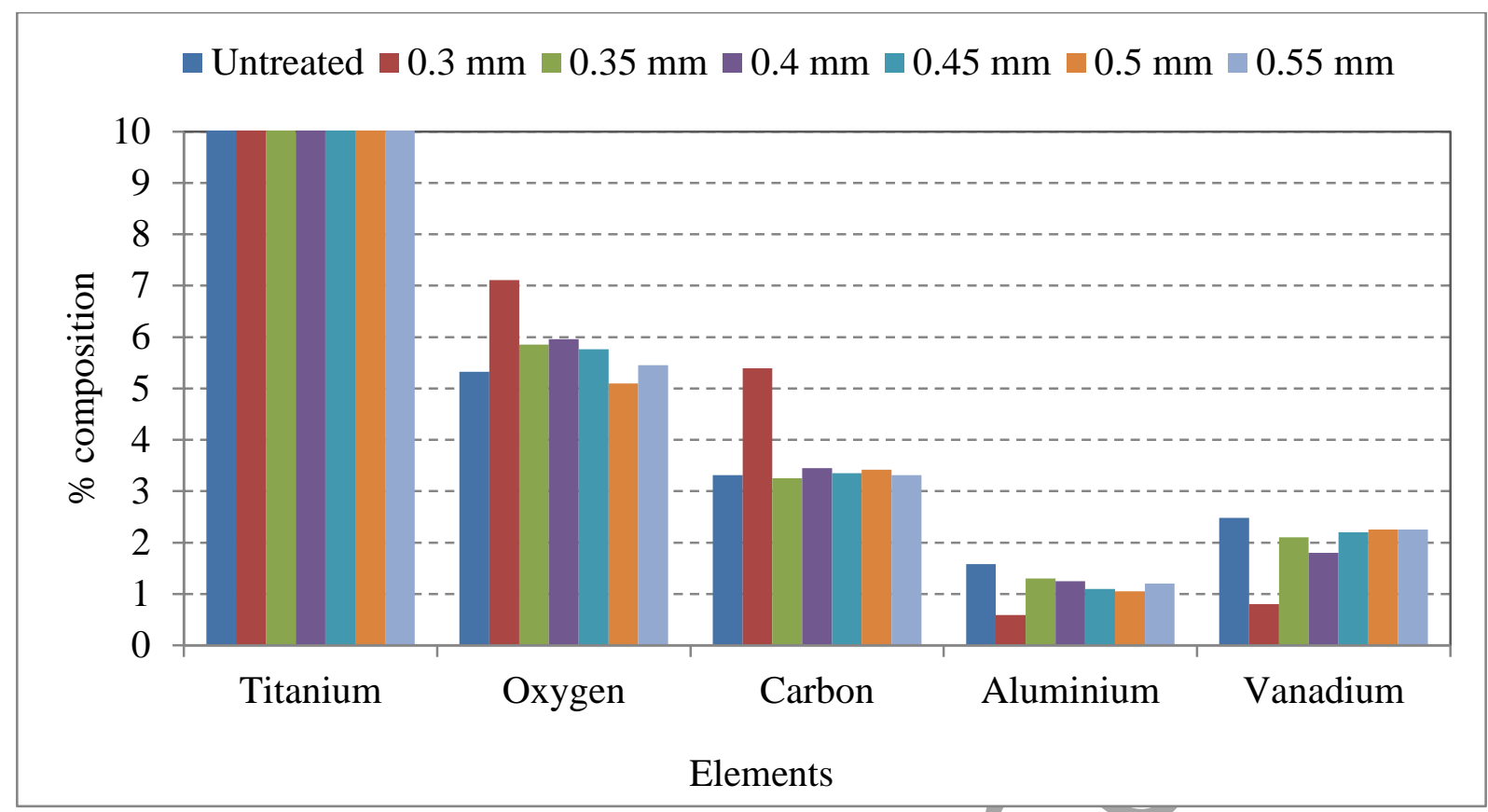

Figure 6 Effect of laser beam offset (in $\mathrm{mm}$ ) on elemental composition of laser polished surface $($ power $=160 \mathrm{w}$, speed $=750 \mathrm{~mm} / \mathrm{sec})$

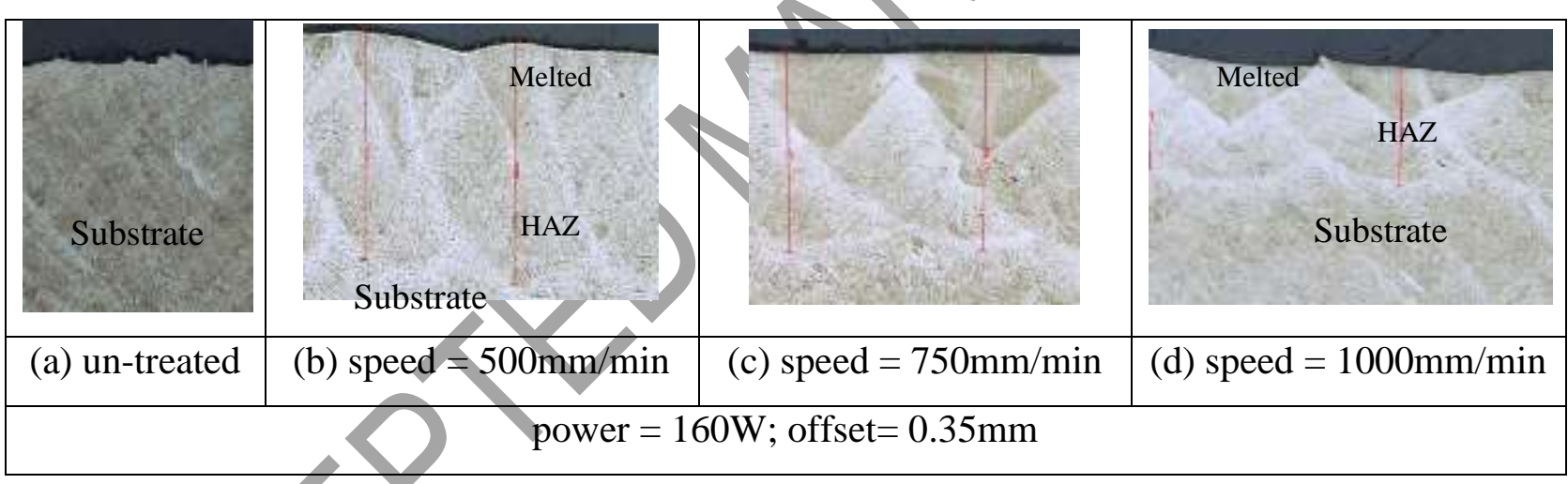

Figure 7 Typical microstructure observed in laser polished SLM sample, showing the effects of scan speed

Cross-sectional laser polished samples were analysed to confirm the sub-surface metallurgical characteristics and is shown in Fig. 7. The service performance of laser polished components depends strongly on the microstructure. Figure 7 shows a typical microstructure observed in laser polishing of Ti-6Al-V4 (power $=160 \mathrm{~W}$, offset $=0.35 \mathrm{~mm}$ ). There was no significant change in the columnar microstructure of the Ti6AlV4 before and after laser polishing. This is attributed to the fact that additive manufacturing of samples involves the melting and solidification of powder particles, which have a similar cooling rate as observed with laser 
polishing. However, additive manufacturing was performed in an inert atmosphere, whilst the current laser polishing was performed in ambient condition with argon gas shielding.

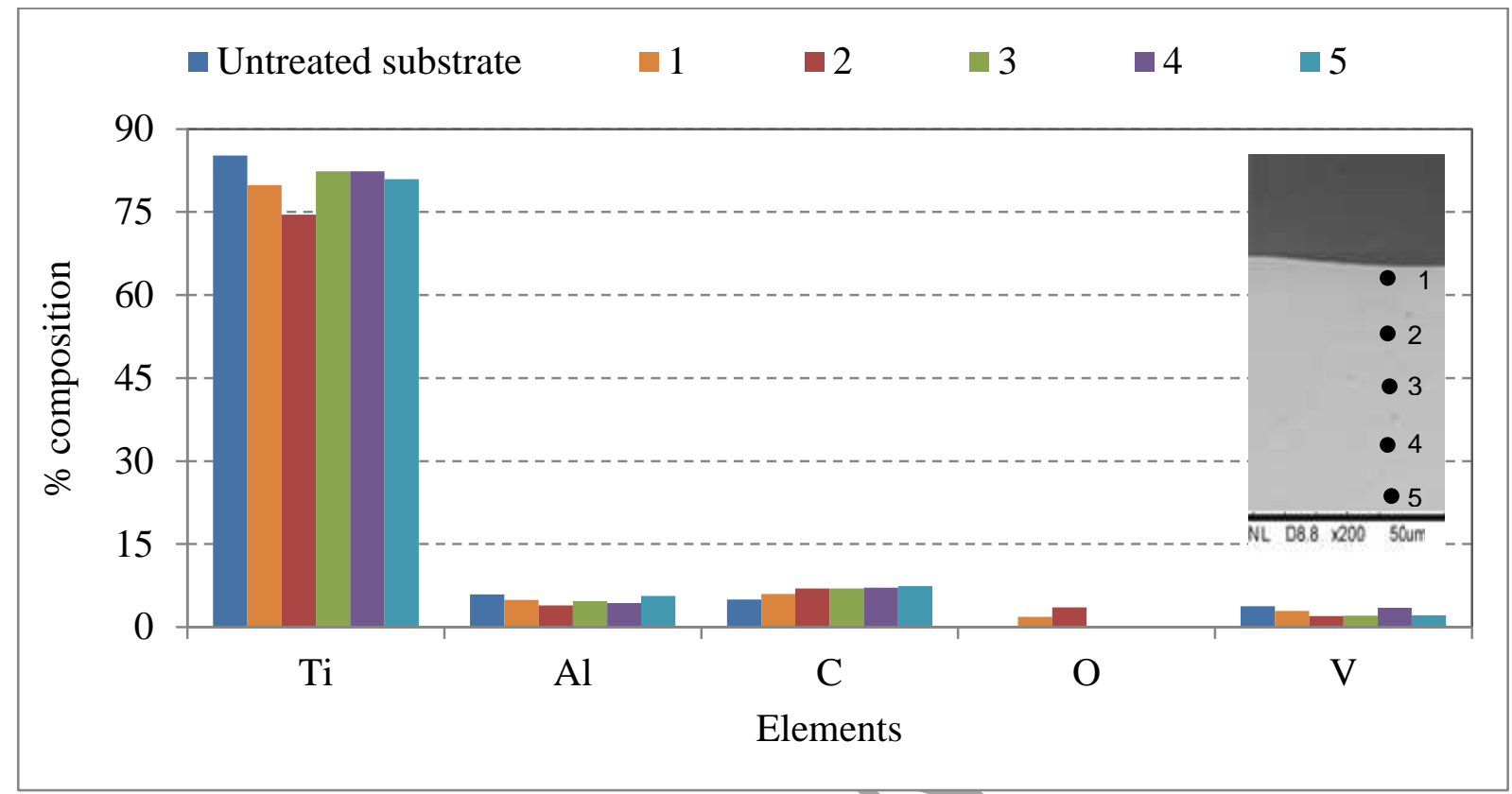

Figure 8 Sub-surface EDAX composition of laser polished sample (power $=160 \mathrm{~W}$, speed $=$ $750 \mathrm{~mm} / \mathrm{sec}$, offset $=0.35 \mathrm{~mm})($ inside image shows different region of the test location)

Figure 8 shows the sub-surface composition of the laser polished Ti-6Al-V4 samples (power of $160 \mathrm{~W}$, scan speed of $750 \mathrm{~mm} / \mathrm{s}$ and scan offset of $0.35 \mathrm{~mm})$. The laser polished sub-surface materials (region 1, 2, 3) showed similar EDAX chemical composition to an unpolished substrate, which confirms the ability of laser polishing process to produce smooth surface without damage to the substrate.

\section{Discussions}

Precise control of the laser energy input is a key requirement for laser surface polishing of SLM parts. One of the key requirements of industrial laser polishing process is the productivity. Higher productivity can be achieved with high scanning speed and low energy input. 
Laser power and scanning speed has significant control on the melt track and its surface morphology during the laser polishing process. As seen from Figure 3, with increasing laser power, the melt width increases linearly, reaching a threshold at $\sim 160 \mathrm{~W}$. With further increases in input energy, the surface condition starts to deteriorate (Fig. 2(f)). Similar effects were noticed when changing speed for a constant power, with low speed resulting in more striation patterns over the substrate surface. At an optimal speed the striation patterns disappeared and a uniform surface was achieved. Further increases in speed resulted in small track width. This is an important phenomenon and this should be attributed to the changes in heat transfer mechanisms within the melt pool. As the experimental visualisation of melt pool was a challenging task, a CFD based numerical analysis, as discussed in literature [25], was used to further analyse the heat transfer mechanisms and change of surface morphology (surface ripples) during the laser polishing process.

The CFD model used in this work is based on the Navier-Stokes equations with K-epsilon formulation. The rate of transport of materials within the melt zone depends on the magnitude of convection fluid flow during laser polishing. The forces that influence the molten pool dynamics and convection fluid flow are primarily the surface tension, viscous and buoyancy forces [26]. From these, surface tension forces dominate [27] influencing the fluid flow to a much higher extent than the buoyancy or viscous forces. In-line with the experimental parameter, the laser spot diameter of the beam over the sample surface was maintained at $0.5 \mathrm{~mm}$ and the beam spatial distribution was considered as a typical Gaussian profile. The thermo-physical properties of the materials can be noted from literatures [23, 24].

Figure 9 shows the melt zone velocity obtained from the CFD simulation for three laser powers. The velocity inside the melt pool is strongly influenced by the surface tension gradient of the material (due to Marangoni convection), which depends upon the surface 
temperature gradient and the maximum temperature. The negative surface tension coefficient in the Ti-6Al-4V melt pool causes an outward flow (Fig. 9), which provides efficient transfer of heat from the centre to the periphery of the pool and through the sample depth. Relatively low flow velocities are found for a laser power of $120 \mathrm{~W}(\sim 0.18 \mathrm{~m} / \mathrm{s})$ and $160 \mathrm{~W}(\sim 0.25 \mathrm{~m} / \mathrm{s})$, whilst considerably higher velocities are found for a higher laser power of $200 \mathrm{~W}(0.46 \mathrm{~m} / \mathrm{s})$.

(a)

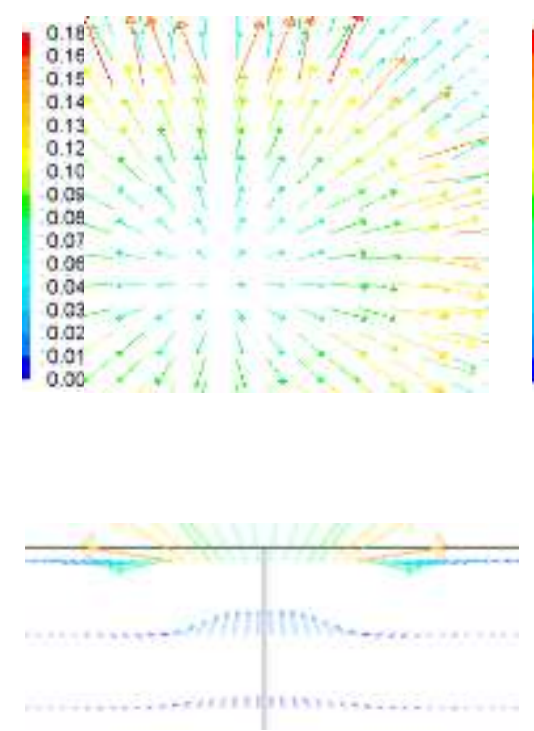

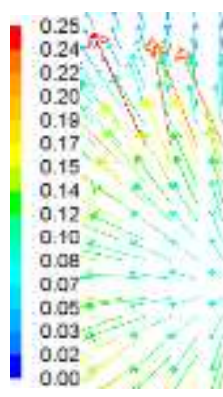

(b)

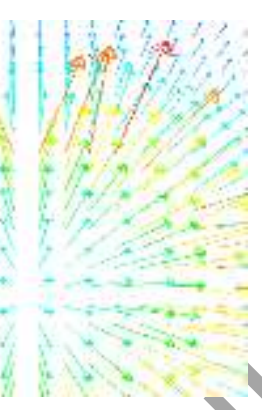

Top View (c)

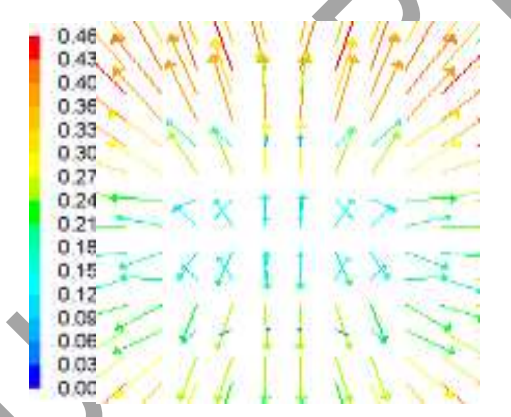

Midpoint cross-section transverse to polishing direction

Figure 9 Comparison of top surface velocity vector (m/s) for laser power of: a) $120 \mathrm{~W}, \mathrm{~b}$ )

$160 \mathrm{~W}$, c) $200 \mathrm{~W}$, with a constant speed of $600 \mathrm{~mm} / \mathrm{min}$

Figure 10 details the liquid fraction contours and the corresponding fusion zone profiles for the three laser powers of $120 \mathrm{~W}, 160 \mathrm{~W}$ and $200 \mathrm{~W}$ respectively. The width of the melt pool increases with laser power, however the rate of increase falls exponentially beyond the threshold limit of $\sim 160 \mathrm{~W}$. Laser powers below $160 \mathrm{~W}$ have resulted in a low melt pool width, due to insufficient thermal energy, rendering it unsuitable for laser polishing. As noted from Figure 10 , laser powers less than $160 \mathrm{~W}$, resulted in a smooth surface profile, with a noticeable change in surface profile for laser powers greater than $160 \mathrm{~W}$. The change in surface profile (hump formation) is primarily attributed to the high melt pool velocity and its direction. 
Increase in laser power result in higher melt pool velocity. Increased melt pool velocity, along with the negative surface tension co-efficient, forced the molten material on the surface to flow outwards $[18,25]$, causing a hump at the middle of the melt pool and a depression close to the melt pool boundary $[18,25]$, which is evident from the liquid fraction contour shown in Figure 10. This higher velocity in the melt pool results in a deterioration of the surface topology. Low velocity in the melt pool, at laser power of $160 \mathrm{~W}$, shows a fusion zone with relatively homogeneous surface and optimal melt width. As noted from the velocity vector and liquid fraction results, it is evident that the initial heat from the laser beam increased the melt pool width. With further increase in laser power, the rate of increase of melt pool width drops, and the thermal energy increases the velocity of the melt pool.

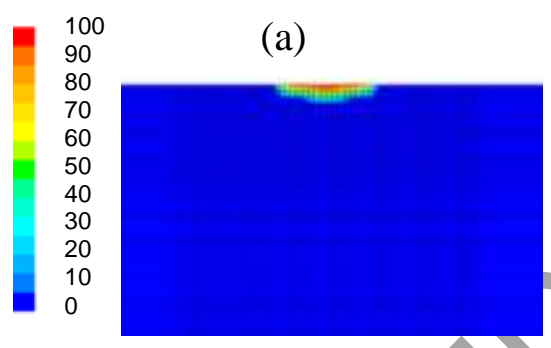

(b)

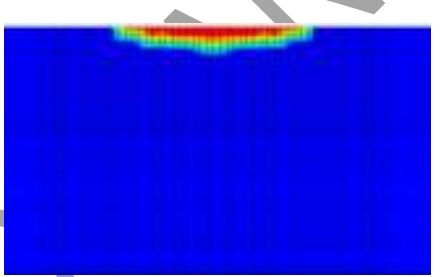

(c)

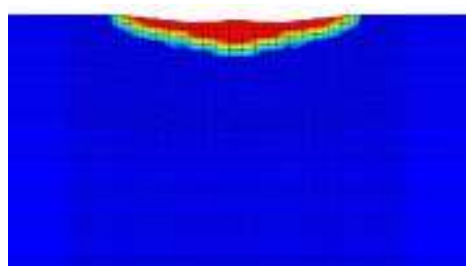

Figure 10 Comparison of liquid fraction (\%) along the midpoint cross-section transverse to polishing direction, showing the change in surface topology of: a) $120 \mathrm{~W}, \mathrm{~b}) 160 \mathrm{~W}$, c) $200 \mathrm{~W}$, with a constant speed of $600 \mathrm{~mm} / \mathrm{min}$

Figure 11 shows the effect of laser power on experimental track (Figure-3) width and simulation melt pool velocity. A non-linear variation was noticed with the increase in laser power for both track width and melt pool velocity. With increase in laser power (50-120W), the track width initially increases slowly $(<120 \mathrm{~W})$, which was associated with low melt pool velocity $(<0.18 \mathrm{~m} / \mathrm{s})$. With further increase in laser power $(120-160 \mathrm{~W})$, the track width increases linearly (20\%), along with a linear increase in melt pool velocity (21\%). This increase in track width can be attributed to an optimal melt pool velocity, which helps effective heat transfer from the beam center to the periphery [28]. With further increase in 
laser power (160-200W), the rate of increase of track width reduces $(\sim 7 \%)$, however, the velocity of the melt pool increases significanlty (110\%). In this range of laser power (>160W), most of the heat input goes on increasing the velocity rather than increasing the track width. The increase in velocity results in changes to the surface morphology of the melt pool surface and efficitive heat transfer to the bottom of the melt pool.

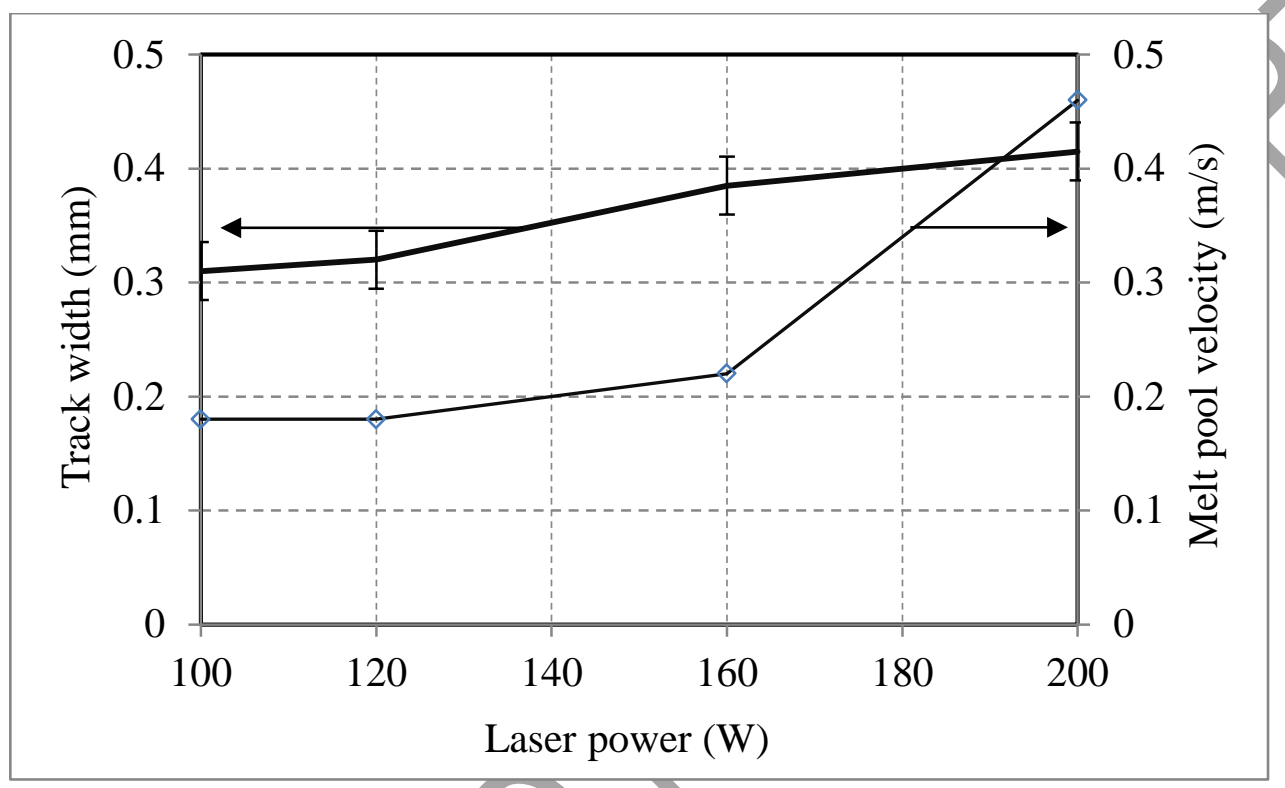

Figure 11 Effect of laser parameters on track width and melt pool convection $($ speed $=$ $600 \mathrm{~mm} / \mathrm{min}$ )

The slight increase in surface oxygen concentration observed in Figure 6 is related to either oxide or alpha case formation. Similar effect was noted on the top layer of sub-surface microstructure as shown in Figure 8. Oxide formation in continuous wave laser processing of Ti-6Al-V4 cannot be fully avoided [15]. However, formation of alpha case can result in significant depreciation of mechanical performance due to crack formation and hence it should be fully avoided. 

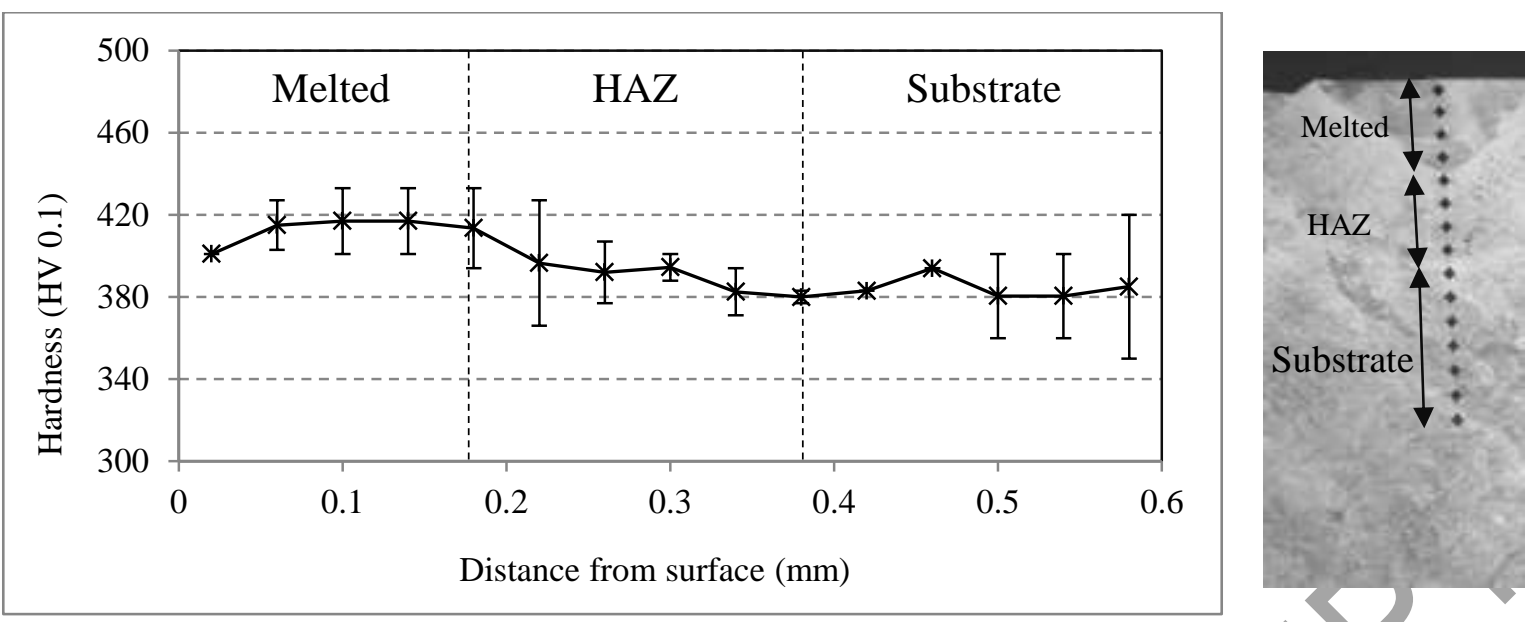

Figure 12 Sub-surface characteristics of laser polished sample $($ power $=160 \mathrm{w}$, speed $=$ $750 \mathrm{~mm} / \mathrm{sec}$, offset $=0.35 \mathrm{~mm})$

Alpha case formation can be identified by analysing the oxygen concentration of the material or its hardness. The maximum oxygen content in the substrate and surface was found to be less than 10\% (Figure 6 and 8), which confirms the non-existence of the no alpha case. To further confirm the non-existence of the no alpha case, micro-hardness test was carried out along the cross-section (from the top surface), as shown in Figure 12. There were no significant variations in hardness along the depth of the laser polished sample, which firstly confirmed the non-existence of alpha-case, and secondly that laser polishing did not change the sub-surface characteristics of the additive manufactured sample.

\section{Conclusions}

Numerical and experimental investigations were carried out for better understanding of continuous wave fibre laser polishing process. Results have been presented with suitable illustrations. The following important conclusions could be drawn from the study.

Continuous wave laser polishing can be used to polish metals and alloys without noticeable changes to it's mechanical or metallurgical characteristics. Specifically there was no evidence of alpha case formation or thermal cracking after laser polishing. 
Excessive thermal energy input during the laser polishing process can result in surface oxidation and carbonisation.

Surface roughness of the laser polished region significantly depends on the melt pool velocity, which itself is influenced by the laser power and speed.

Increase in input energy result in increased meltpool velocity, which subsequently generates periodic striation patterns in the laser polished surface and should be avoided. A laser polished zone with good surface profile and roughness can be achieved by restricting the melt pool convection to a minimum.

Low meltpool velocity helps achieve wider laser polished track width. Increase in melt pool velocity increases the melt pool depth without significant increase in meltpool width, which is not ideal for laser polishing.

\section{Acknowledgement}

The authors acknowledge the financial support of the work by the Technology Strategy Board (TSB) under the IMPULSE grant. The authors gratefully acknowledge 3T RPD Ltd. for supplying the additive manufactured samples used in the experiments.

\section{References}

1. Sims, C.T.; Stoloff, N.S.; Hagel, W.C. Superalloys ii. 2nd ed 1987, New York: WileyBlackwell.

2. Ashby, M.F. Materials and the Environment: Eco-Informed Material Choice 2009, Burlington, MA: Butterworth-Heinemann.

3. Toyserkani, E.; Khajepour, A.; Corbin, S. Laser cladding 2005: CRC Press.

4. Alimardani, M.; Toyserkani, E.; Huissoon, J.P. A 3D dynamic numerical approach for temperature and thermal stress distributions in multilayer laser solid freeform fabrication process. Optics and Lasers in Engineering, 45, 1115-1130 (2007). 
5. Clark, D.; Bache, M.R.; Whittaker, M.T. Shaped metal deposition of a nickel alloy for aero engine applications. Journal of Materials Processing Technology, 203, 439-448 (2008).

6. Yasa, E.; Kruth, J.-P. Microstructural investigation of Selective Laser Melting 316L stainless steel parts exposed to laser re-melting. Procedia Engineering, 19, 389-395 (2011).

7. Li, Y.; Wu, Y.; Zhou, L.; Fujimoto, M. Vibration-assisted dry polishing of fused silica using a fixed-abrasive polisher. International Journal of Machine Tools and Manufacture, 77, 93-102 (2014).

8. Tsai, M.-Y.; Yang, W.-Z. Combined ultrasonic vibration and chemical mechanical polishing of copper substrates. International Journal of Machine Tools and Manufacture, 53, 69-76 (2012).

9. Habibzadeh, S.; Li, L.; Shum-Tim, D.; Davis, E.C.; Omanovic, S. Electrochemical polishing as a $316 \mathrm{~L}$ stainless steel surface treatment method: Towards the improvement of biocompatibility. Corrosion Science, 87, 89-100 (2014).

10. Ukar, E.; Lamikiz, A.; López de Lacalle, L.; del Pozo, D.; Arana, J. Laser polishing of tool steel with $\mathrm{CO} 2$ laser and high-power diode laser. International Journal of Machine Tools and Manufacture, 50, 115-125 (2010).

11. Kumstel, J.; Kirsch, B. Polishing titanium-and nickel-based alloys using cw-laser radiation. Physics Procedia, 41, 355-364 (2013).

12. Lamikiz, A.; Sanchez, J.; Lopez de Lacalle, L.; Arana, J. Laser polishing of parts built up by selective laser sintering. International Journal of Machine Tools and Manufacture, 47, 2040-2050 (2007).

13. Dadbakhsh, S.; Hao, L.; Kong, C.Y. Surface finish improvement of LMD samples using laser polishing. Virtual and Physical Prototyping, 5, 215-221 (2010).

14. Tian, Y.S.; Chen, C.Z.; Li, S.T.; Huo, Q.H. Research progress on laser surface modification of titanium alloys. Applied Surface Science, 242, 177-184 (2005).

15. Molchan, I.S.; Marimuthu, S.; Mhich, A.; Liu, Z.; Hashimoto, T.; Thompson, G.E.; Whitehead, D.; Wang, Z.B.; Mativenga, P.; Li, L.; Grafton-Reed, C.; Leaver, I.H.; Cheetham, S.; Dilworth, S. Effect of surface morphology changes of Ti-6Al-4V alloy modified by laser treatment on GDOES elemental depth profiles. Journal of Analytical Atomic Spectrometry, 28, 150-155 (2013). 
16. Roberts, I.A. Investigation of residual stresses in the laser melting of metal powders in additive layer manufacturing, 2012, Doctoral dissertation, University of Wolverhampton.

17. Suder, W.; Williams, S. Investigation of the effects of basic laser material interaction parameters in laser welding. Journal of Laser Applications, 24, 032009 (2012).

18. Li, L.; Eghlio, R.; Marimuthu, S. Laser net shape welding. CIRP Annals Manufacturing Technology, 60, 223-226 (2011).

19. Fluent 13.0 User's Guide. ANSYS Inc (2009).

20. Mazumder, J.; Steen, W. Heat transfer model for CW laser material processing. Journal of Applied Physics, 51, 941-947 (1980).

21. Phanikumar, G.; Chattopadhyay, K.; Dutta, P. Modelling of transport phenomena in laser welding of dissimilar metals. International Journal of Numerical Methods for Heat \& Fluid Flow, 11, 156-174 (2001).

22. Amara, E.H.; Fabbro, R. Modeling of humps formation during deep-penetration laser welding. Applied Physics A: Materials Science and Processing, 101, 111-116 (2010).

23. Boivineau, M.; Cagran, C.; Doytier, D.; Eyraud, V.; Nadal, M.-H.; Wilthan, B.; Pottlacher, G. Thermophysical properties of solid and liquid Ti-6Al-4V (TA6V) alloy. International journal of thermophysics, 27, 507-529 (2006).

24. Collings, E.; Welsch, G.; Boyer, R. Materials properties handbook: titanium alloys. ASM International 1 (1994).

25. Marimuthu, S.; Eghlio, R.M.; Pinkerton, A.J.; Li, L. Coupled computational fluid dynamic and finite element multiphase modeling of laser weld bead geometry gormation and joint strengths. Journal of Manufacturing Science and Engineering, 135,011004 (2013).

26. He, X.; Fuerschbach, P.; DebRoy, T. Heat transfer and fluid flow during laser spot welding of 304 stainless steel. Journal of Physics D: Applied Physics, 36, 1388 (2003).

27. DebRoy, T.; David, S. Physical processes in fusion welding. Reviews of Modern Physics, 67, 85 (1995).

28. Raghavan, A.; Wei, H.L.; Palmer, T.A.; DebRoy, T. Heat transfer and fluid flow in additive manufacturing. Journal of Laser Applications, 25, 052006 (2013). 